\title{
Translational efficiency of casein transcripts in the mammary tissue of lactating ruminants
}

\author{
Claudia Bevilacqua, Jean Christophe Helbling, Guy MirandA, \\ Patrice MARTIN*
}

INRA, Unité Génomique et Physiologie de la Lactation, Équipe Gel-Pict, 78352 Jouy-en-Josas Cedex, France

\begin{abstract}
Caseins are essentially concentrated in the colloidal fraction of ruminant milks as highly hydrated and mineralized spherical particles, termed casein micelles. They form a group of four peptide chains $\left(\alpha_{\mathrm{s} 1}, \beta, \alpha_{\mathrm{s} 2}\right.$ and $\left.\kappa\right)$, encoded by four structural genes (CSN1S1, CSN2, CSN1S2 and CSN3, respectively) of which the expression is regulated by lactogenic hormones. These phosphoproteins are synthesized, essentially during lactation, in the mammary epithelial cells and we show, for the first time, that their regulation is also controlled at the translational level. Apparently, the four casein messenger are not translated with the same efficiency. Specific amplification systems have been developed and optimized to quantify, by real time quantitative PCR (qPCR), transcripts encoding the four caseins starting from total RNA extracted from mammary tissues taken on goats $(n=4)$, ewes $(n=3)$ and cows $(n=3)$, in lactation. The relative proportions of each specific messenger ( $\%$ of casein mRNA) were compared to the relative amounts of the corresponding caseins (\% of whole casein) in milks sampled from the same animals, determined after fractionation by reverse phase HPLC and integration of the corresponding peak areas. From qPCR data, the four casein transcripts appeared to be present approximately at the same level of abundance (ca. 25\%, except for defective genotypes at the CSN1S1 locus, in the goat) whereas the amounts of the corresponding proteins in milk were ranging between 9 and $38 \%$ of the whole casein fraction. A comparison of specific translational efficiencies (\% of protein in milk/\% of transcript in the mammary tissue), showed that $\alpha_{\mathrm{s} 1^{-}}$and $\beta$-casein transcripts are translated ca. 3- to 4-fold more efficiently than $\alpha_{\mathrm{s} 2^{-}}$ and $\kappa$-casein transcripts. This seems to be the rule in the three ruminant species studied. More or less optimal contexts for initiation of translation (Kozak recognition sequence of the start codon) as well as 3' untranslated region (UTR) sequences and length might explain, at least in part, our results. These preliminary results which have now to be confirmed with a larger number of individuals to strengthen our findings and conclusions, provides, however, a rational explanation to the unbalanced casein distribution (approximate proportions $4: 1: 4: 1$ for $\alpha_{\mathrm{s} 1}: \alpha_{\mathrm{s} 2}: \beta: \kappa$, respectively) reported for ruminant milks. The possible effects of specific secondary structures in the 5' and 3' UTRs of casein messengers still have to be considered.
\end{abstract}

milk / casein / mRNA / quantification / untranslated regions (UTRs) / RP-HPLC / real time quantitative PCR / goat / cow / ewe

\section{INTRODUCTION}

In cattle, caseins are essentially concentrated in the colloïdal fraction of milk as highly hydrated and mineralized spheri-

\footnotetext{
* Corresponding author: patrice.martin@jouy.inra.fr
}

cal particles: the so-called casein micelles. Caseins comprise a group of four peptide chains $\left(\alpha_{\mathrm{s} 1}, \beta, \alpha_{\mathrm{s} 2}\right.$ and $\left.\kappa\right)$ resulting from the expression of four structural genes (CSN1S1, CSN2, CSN1S2 and CSN3, respectively), clustered in a 250-kb DNA segment (casein locus), of which the first three are evolutionary related ([1] for a review). 


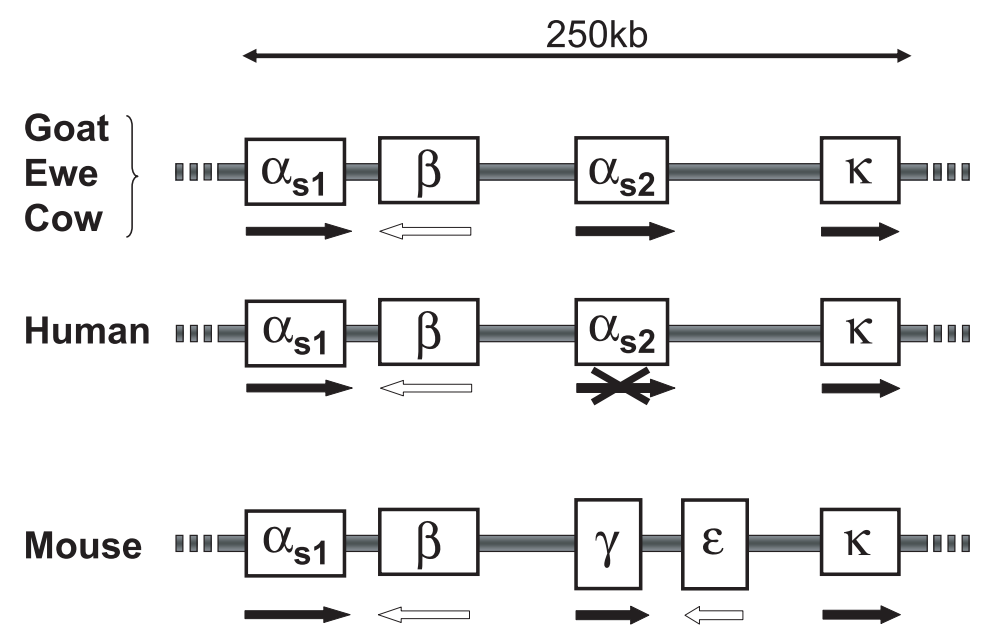

Figure 1. Genomic organization of the casein locus in different species. The genes encoding caseins are depicted by white boxes. Despite some differences in the number of casein genes (with an extra $\alpha_{\mathrm{s} 2}$-like gene, the mouse and human loci comprises 5 transcription units), the overall structural organization of this locus is fairly conserved between mammalian species. In the human locus, $\alpha_{\mathrm{s} 2 \mathrm{a}}$ like gene is transcribed (possibly not translated) whereas $\alpha_{\mathrm{s} 2 \mathrm{~b}}$-like gene is silent [25]. Horizontal arrows (white and black) show the transcription direction.

The genomic organisation of this casein locus is highly conserved between mammals (Fig. 1).

The four caseins represent $80 \%$ of cow milk proteins [2]. From one species to another, a large variability (quantitative as well as qualitative) is observed [3]. In human milk, there are only three caseins $[4,5]$, whereas in murine and rabbit milks there are five $[6,7]$. These extreme situations reflect a general phenomenon which can take more subtle appearances, in which relative proportions of caseins may vary significantly between species and even between individuals, within species. This is particularly exemplified, as far as $\alpha_{\mathrm{s} 1^{-}}$and $\beta$-caseins are concerned, in the goat species [8]. A minimum of 17 alleles have so been far characterized at the CSN1S1 locus [9], distributed among seven different classes of protein variants, associated with four levels of expression ranging between $0\left(\alpha_{\mathrm{s} 1}-\mathrm{Cas} \mathrm{O}\right)$ and 3.5 g. $\mathrm{L}^{-1}\left(\alpha_{\mathrm{s} 1}\right.$-CasA, B, C and $\left.\mathrm{M}\right)$ per allele. The $\mathrm{E}$ variant with an intermedi- ate expression level (1.1 g.. $\mathrm{L}^{-1}$ per allele) is 199 amino acid residues in length and only differs from strong variants (A, B, $\mathrm{C}$ and $\mathrm{M}$ ) by single point mutations [10]. The $\mathrm{F}$ variant which is weakly expressed (0.6 g.L $\mathrm{L}^{-1}$ per allele) displays an internal deletion of 37 amino acids [11], leading to the loss of five contiguous phosphoseryl residues. This deletion arises from the outsplicing of three exons $(9,10$ and 11) during the processing of primary transcripts, due to a single nucleotide deletion within the first (exon 9) unspliced exon. The occurrence of a premature stop codon promotes nonsense-mediated mRNA decay (NMD) accounting for the weak expression of this allele.

Thus, the regulation of gene expression can be controlled, mostly by the non coding portion of the genome, through a series of complex mechanisms at several levels, including transcription, pre-mRNA splicing and export, mRNA stability, translation, etc. Regarding caseins, the translational level is undoubtedly the less 
explored so far. To shed some light on this way of regulation, we undertook the quantification of expression products (mRNA and proteins) from genes encoding caseins in three ruminant species: cattle, sheep and goats.

Specific PCR amplification systems have been designed and optimized to quantify transcripts encoding each casein, in the three species. Caseins were fractionated using RP-HPLC and quantified by integration of the respective peak areas. A comparison of relative expression levels (protein/mRNA ratios) between casein encoding genes provides a valuable mean to evaluate the translation efficiency of each messenger. Interestingly, here we first provide strong evidence that casein specific messengers are not translated with the same efficiency.

\section{MATERIALS AND METHODS}

\subsection{Animals}

Four goats (Alpine and Saanen), three ewes (Lacaune) and three cows (Prim Holstein) at the same number and the same stage of lactation were sampled for milk and mammary gland tissue (taken after slaughtering). Milk was kept at $4{ }^{\circ} \mathrm{C}$ before skimming by centrifugation at room temperature. Immediately after collection, mammary tissues were washed with PBS solution and deep frozen in liquid nitrogen. Then, they were conserved at $-80{ }^{\circ} \mathrm{C}$. Goats have been genotyped at the CSN1S1 locus [12].

\subsection{Milk sampling and RP-HPLC analyzed}

Milk samples were skimmed by centrifugation (4000 rpm; $4{ }^{\circ} \mathrm{C}, 10 \mathrm{~min}$ ) and kept frozen at $-20^{\circ} \mathrm{C}$. For analysis by RPHPLC, skimmed milks were first clarified by the addition of 7 volumes to cow and goat milks and 23 volumes to ewe milk of $0.1 \mathrm{M}$ bis-Tris buffer, $\mathrm{pH} 8.0$, containing $8 \mathrm{M}$ urea, $1.3 \%$ trisodum citrate and $0.3 \%$ DTT [13]. Clarified milk samples $(100 \mu \mathrm{L})$ were then injected directly on the RP-HPLC column.

The chromatographic apparatus comprised a BioCad Sprint System (Perkin Elmer, Norwalk, CT, USA) equipped with a variable wavelength double detector and an automatic collector (Advantec, Tokyo, Japan). Milk samples were analysed on a Vydac C4 Reverse Phase column 214 TP $54(300 \AA$ pore size, $5 \mu \mathrm{m}, 4.6 \mathrm{~mm}$ I.D., $150 \mathrm{~mm}$; Touzart and Matignon, Vitry sur seine, France). Elution solvents were the following: solvent A (TFA/ $\mathrm{H}_{2} \mathrm{O}$ $1.15: 1000 \mathrm{v} / \mathrm{v}$ ) and solvent B (TFA/ACN 1:1000 v/v). The Elution was achieved by a one step linear gradient: $25 \%$ to $50 \%$ solvent $\mathrm{B}$ over $60 \mathrm{~min}$ at a flow rate of $1 \mathrm{~mL} \cdot \mathrm{min}^{-1}$. The eluant absorbance was continuously monitored at $214 \mathrm{~nm}$. For goat and cow milk samples the column was maintained at $40^{\circ} \mathrm{C}$ and for ewe milk it was maintained at $50{ }^{\circ} \mathrm{C}$.

\subsection{RNA extraction and cDNA synthesis}

Total RNA were isolated from mammary tissue samples taken from three different animals within each species (cattle, sheep and goats), using TRIzol Reagent (Invitrogen Life Technologies, Carlsbad, California, USA) according to the manufacterer's instructions.

RNA quality was analyzed using two independent techniques. A NanoDrop ND1000 spectrophotometer (Nixor Biotech) was first used to record the absorbance at multiple wavelengths: $230 \mathrm{~nm}$ and $320 \mathrm{~nm}$ (background absorption and possible contaminants), $260 \mathrm{~nm}$ (nucleic acids) and $280 \mathrm{~nm}$ (proteins). On the basis of ratios (260/230 and 260/280) at these different wavelengths, the quantity, quality, purity and extraction performance were estimated. 
Table I. Primers used in this study. Each pair of primers amplifies the target cDNA (amplicon sizes ranging between 61-76 nucleotides) in the 3' region. Primer pairs were designed with the Primer Express Software v2.0 (Applied Biosystems) except for $24 \mathrm{~S}$ ribosomal protein primers which were manually designed.

\begin{tabular}{lllc}
\hline Genes & Primers & Sequence ${ }^{\prime} \longrightarrow 3$ & Amplicon size \\
\hline$\alpha_{\text {s1 }}$-casein & Forward & TCC ACT AGG CAC ACA ATA CAC TGA & $61 \mathrm{nt}$ \\
$($ CSN1S1 $)$ & Reverse & GCC AAT GGG ATT AGG GAT GTC & \\
$\alpha_{\text {s2 }- \text {-casein }}$ & Forward & AAC ATG CTG GTT GTA TGA AGT AAA GTG & $76 \mathrm{nt}$ \\
$($ CSN1S2 $)$ & Reverse & CTG GTT ATG GTT GGA CTG GAAAA & \\
$\beta$-casein & Forward & CTG GAC CAG AGC CAG AGG AA & $71 \mathrm{nt}$ \\
$($ CSN2 $)$ & Reverse & GAA AGC CAG AGC CTG ACT CTC A & \\
$\kappa$-casein & Forward & AGG TGC AAT GAT GAA GAG TTT TTT C & $66 \mathrm{nt}$ \\
$($ CSN3 $)$ & Reverse & CCC AAA AAT GGC AGG GTT AA & \\
18 S RNA & Forward & AGA AAC GGC TAC CAC ATC CAA & $59 \mathrm{nt}$ \\
& Reverse & GGG TCG GGA GTG GGT AAT TT & \\
Cyclophilin & Forward & TGA CTT CAC ACG CCA TAA TGG T & $62 \mathrm{nt}$ \\
& Reverse & CAT CAT CAA ATT TCT CGC CAT AGA & \\
24 S ribosomal & Forward & TTT GCC AGC ACC AAC GTT G & $66 \mathrm{nt}$ \\
protein & Reverse & AAG GAA CGC AAG AAC AGA ATG AA & \\
\hline
\end{tabular}

To assess RNA integrity, we used a microcapillary electrophoresis device developped by Agilent Technologies, with the RNA 6000 nano LabChip Kit. The Agilent 2100 Bioanalyzer provides a complementary mean to assess RNA intactness by showing a detailed picture of the size distribution of RNA fragments and giving automatically the $28 \mathrm{~S}$ to $18 \mathrm{~S}$ ribosomal subunits ratio. To get a better and reliable description of RNA quality and standardize the process, the RNA Integrity Number (RIN) introduced by Agilent Technologies [14] was also used.

Four $\mu \mathrm{g}$ of total RNA was then used to make reverse-transcription. First strand cDNA was synthesized using oligodT primers and ROCHE Transcriptor reverse-transcriptase according to the manufacturer's instructions (Roche Applied Science) and subsequently diluted with nuclease free water (Sigma) to yield a final concentration of $0.2 \mathrm{ng} . \mu \mathrm{L}^{-1}$.
No DNAse treatment was carried out to remove contaminating genomic DNA (see below).

\subsection{Primer design and Real-Time quantitative PCR}

Expression levels of $\alpha_{\mathrm{S}^{-}}, \alpha_{\mathrm{S} 2^{-}}, \beta-$ and $\kappa$-casein genes were measured using RealTime quantitative PCR (qPCR). Three internal control genes (cyclophilin, 24S ribosomal protein and 18S ribosomal RNA) were tested for accurate normalization of data.

Primer pairs were designed with the Primer Express Software v2.0 (Applied Biosystems) except for $24 \mathrm{~S}$ ribosomal protein primers which were manually designed. To eliminate the risk for genomic DNA amplification we systematically chose primers that hybridize on exonexon junctions. Primers, for which the sequences are given in Table I, were purchased from MWG Biotech (France). 
The qPCR amplification mixture $(20 \mu \mathrm{L})$ contained $5 \mu \mathrm{L}$ single strand cDNA template $(1 \mathrm{ng}), 10 \mu \mathrm{L} 2 \mathrm{X}$ SYBR Green PCR Master Mix buffer (Applied Biosystems) and 1.2 $\mu \mathrm{L}$ forward and reverse primers $(5 \mu \mathrm{M})$ to reach a final primer concentration of $300 \mathrm{nM}$. The reaction was run (in triplicate) on an ABI PRISM 7900HT Sequence Detection System (Applied Biosystems). The cycling conditions comprised 2 min UNG activation at $50{ }^{\circ} \mathrm{C}, 10 \mathrm{~min}$ polymerase activation at $95{ }^{\circ} \mathrm{C}$ and 40 cycles at $95^{\circ} \mathrm{C}$ for $15 \mathrm{~s}$ and $60{ }^{\circ} \mathrm{C}$ for $60 \mathrm{~s}$. Each assay included in duplicate a standard curve of four serial dilution points of a cDNA pool ( 3 goats, 3 ewes and 3 cows, ranging from $10 \mathrm{ng}$ to $0.01 \mathrm{ng}$ cDNA), a no template control (NTC), and $1 \mathrm{ng}$ of each test cDNA. Sequence Detection Software (Applied Biosystems, version 2.1) results were exported as tab-delimited text files and imported into Microsoft Excel for further analysis.

\section{RESULTS AND DISCUSSION}

\subsection{Real Time quantitative PCR of casein mRNA}

\subsubsection{Quantity and quality assessment of RNA samples}

Generation of high-quality gene expression qPCR data is dependent on highquality input RNA. RNA sample purity was directly determined from $\mathrm{A}_{260} / \mathrm{A}_{280}$ and $A_{260} / A_{230}$ ratios which were $>2.0$ signing clean RNA preparations.

RNA integrity was further assessed by resolving the $28 \mathrm{~S}$ and $18 \mathrm{~S}$ ribosomal subunit bands using the Agilent 2100 Bioanalyzer. $28 \mathrm{~S}$ to $18 \mathrm{~S}$ ratios were systematically $\geq 1.8$ and RIN (RNA Integrity Number) values were $9.0 \pm 0.5$. Taken together these data clearly demonstrate that RNA samples were assessed as high-quality preparations ready for downstream gene expression quantitation. The efficiency of the reverse transcription reaction was also controlled using the Agilent 2100 Bioanalyzer.

\subsubsection{Optimization of qPCR assays}

When intercalating dyes such as SYBR green I are used, attention should be paid to the formation of primer-dimers. Genespecific amplification was confirmed for the 4 casein systems $\left(\alpha_{\mathrm{s} 1}, \alpha_{\mathrm{s} 2}, \beta\right.$ and $\left.\kappa\right)$ as well as for the internal controls by a single peak in melt-curve analysis. No primerdimer formation was detected (results not shown).

The four PCR quantitation systems designed to allow amplification of the four casein transcripts in the three ruminant species were shown to amplify targeted transcripts in goats, sheep and cattle mammary RNA samples.

Then, for all the amplification systems studied, including internal controls, we estimated the reaction efficiency by measuring the slope of a standard curve generated by serial dilution of a cDNA pool of known concentration, in each species. The cDNA pool was obtained by mixing 3 cDNA samples yielded from 3 individuals of the same species to minimize individual variations.

With a slope value ranging between -3.50 and -3.30 , which corresponds to an efficiency of the amplification reaction comprised between $93 \%$ and $100 \%$, the seven systems developed and optimized for this study were ready to perform the quantitative analysis of casein transcripts.

To achieve accurate and reproducible expression levels between experiments, we used as a reliable internal control, the $24 \mathrm{~S}$ ribosomal protein gene for normalization. This gene was chosen since it is expressed at the same level in the three different species, during the course of lactation.

\subsection{Casein transcripts quantitation}

The unknown samples were quantified using standard curves and the amount of 


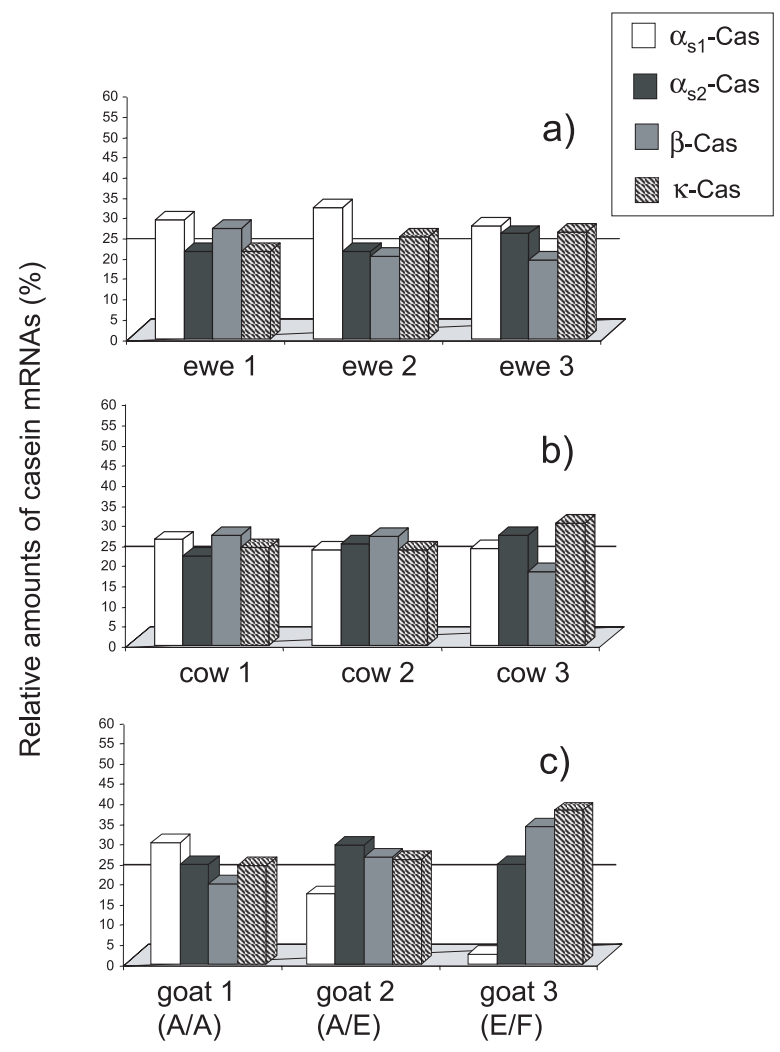

Figure 2. Relative amounts of each casein transcript in the mammary tissue of lactating ewes (a), cows (b) and goats (c). Each casein transcript represents ca. $1 / 4$ of the whole casein transcript population (horizontal bar). The genotype of each goat, at the CSN1S1 locus, is given (c). The percentage of $\alpha_{\mathrm{s} 1}$-Cas mRNA dramatically drops from $30 \%$ for goat $1\left(\alpha_{\mathrm{s} 1}\right.$-CasA/A) to $3 \%$ for goat $2\left(\alpha_{\mathrm{s} 1}\right.$ CasE/F), with an intermediate value $(17 \%)$ for goat $3\left(\alpha_{s 1}-\mathrm{Cas} / \mathrm{E}\right)$.

each casein transcript occurring within each sample was expressed relative to the amount of transcript measured for the single internal control (24S ribosomal protein) used for normalization. Assuming the total of the normalized amounts estimated for the 4 casein transcripts in a sample is 100 , transcripts arising from each casein gene can be expressed as a percentage. In such a way, we calculated the percentages of $\alpha_{\mathrm{s} 1}$-Cas, $\alpha_{\mathrm{s} 2}$-Cas, $\beta$-Cas and $\kappa$-Cas transcripts which appear to be rather constant between individuals within and between species, except for the goat in which the well characterized genetic polymorphism occurring at the CSN1S1 locus is responsible for a significant individual variability. Each casein transcript represents ca. $1 / 4$ of the whole casein transcript population (see Fig. 2).

More precisely, as far as ewes are concerned, $\alpha_{\mathrm{s} 1}$-Cas transcripts are slightly over represented with a percentage ranging between 28 and $33 \%$ of the casein transcripts (Fig. 2a), whereas for the other caseins the amount of messengers is between 20 and $27 \%$. Regarding cattle, except for cow3 (Fig. 2b) for which the amount of $\kappa$-Cas transcripts is slightly higher (30\%) and $\beta$-Cas lower (18\%), the 


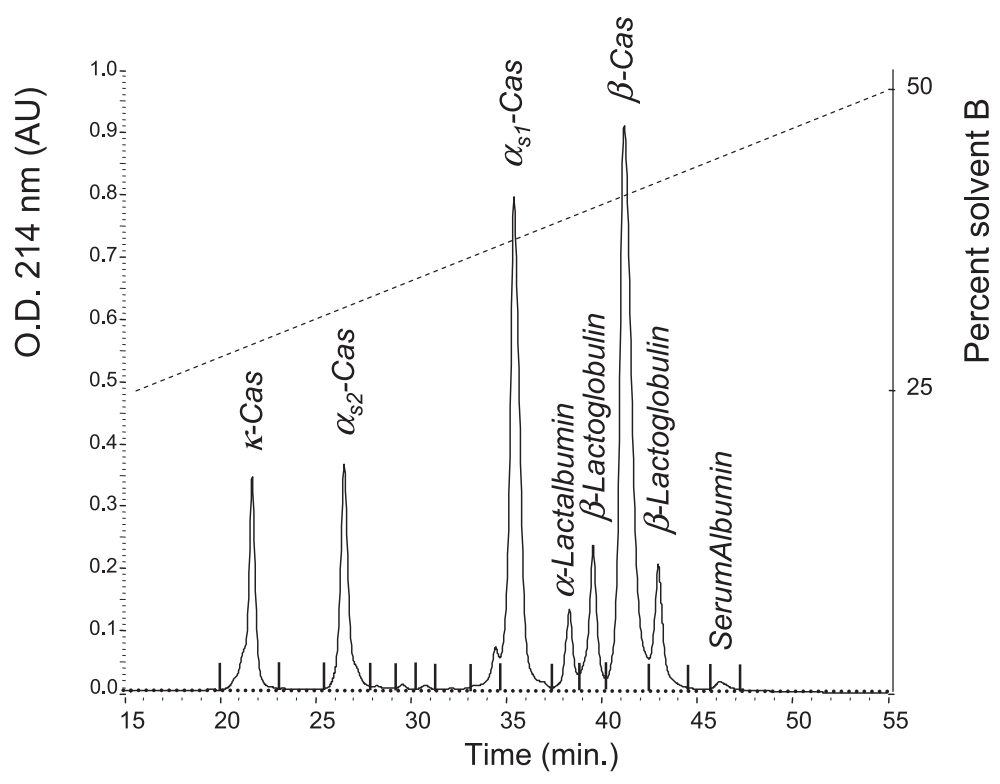

Figure 3. Typical RP-HPLC elution profile of proteins from an individual ewe milk. Thirty microliters of clarified milk sample (day 40 of lactation) were injected on a Vydac $\mathrm{C} 4$ column (see Section Materials and Methods for details). Solvents were: A (TFA/ $\mathrm{H}_{2} \mathrm{O}$ 1.15:1000 v/v) and B (TFA/ACN 1:1000 v/v). The elution was achieved by a one step linear gradient (broken line): $25 \%$ to $50 \%$ solvent B over $60 \mathrm{~min}$ at a flow rate of $1 \mathrm{~mL} \cdot \mathrm{min}^{-1}$.

values are on average more stable and closer to $25 \%$. Conversely, in the goat species, the situation was as expected, given the genotypes of the goats used in this study. Indeed, of the three goats sampled, only one was homozygous for a highly expressed allele (A/A) at the $\alpha_{\mathrm{s} 1^{-}}$ Cas locus whereas the other two bore at least one defective allele $(\mathrm{A} / \mathrm{E}$ and $\mathrm{E} / \mathrm{F})$ at this locus. The occurrence of a defective allele at the $\alpha_{\mathrm{s} 1}$-Cas locus is here clearly evidenced. The percentage of $\alpha_{\mathrm{s} 1}$-Cas mRNA dramatically drops from $30 \%$ for the goat $\alpha_{\mathrm{s} 1}$-CasA/A to $3 \%$ for the goat $\alpha_{\mathrm{s} 1}$-CasE/F, with an intermediate value (17\%) with the goat $\alpha_{\mathrm{s} 1}$-CasA/E (Fig. 2c). To overcome the bias introduced by the genetic polymorphism occurring at the CSN1S1 locus, $\alpha_{\mathrm{s} 1}$ Cas transcripts were ignored and relative proportions of each remaining casein transcripts were re-estimated. In such a way, a compensatory effect can be observed, in- volving both an overexpression of $\kappa$-Cas and, to a lower extent, $\beta$-Cas messengers (data not shown).

\subsection{Quantitative determination of caseins in milk}

A typical elution profile of an individual ewe milk analysed in RP-HPLC is given in Figure 3. Resolution was optimized to allow an accurate quantitation of each protein by integrating peak areas. The areas calculated for the 4 caseins were summed and the relative proportion of each casein was expressed as a percentage of this value (whole casein).

Figure 4 shows means of relative proportions calculated for each casein in the milks of the three species studied. Whatever the species, both $\beta$ - and $\alpha_{\mathrm{s} 1}$-casein (homozygous $\mathrm{A} / \mathrm{A}$ at the CSN1S1 locus) 


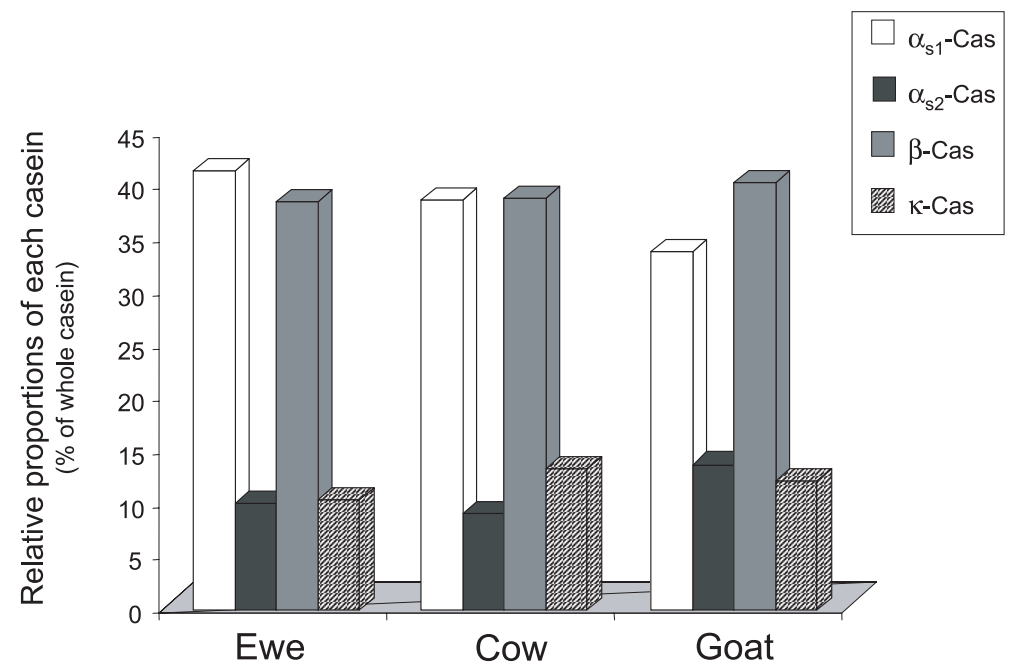

Figure 4. Relative amounts of each casein in ewe, cow and goat milks. Peak areas was shown to increase linearly with the amount of milk injected over a wide range of casein concentrations (results not shown). The amount of each casein in each milk was estimated by integration of the relevant peak area, determined by the absorbance at $214 \mathrm{~nm}$. Histograms are mean values from 3 (ewes and goats) or 2 (cows) individual milk samples.

are major caseins and account each for ca. $38 \%$ of the whole casein fraction. Conversely, $\alpha_{\mathrm{s} 2-}$ and $\kappa$-caseins are less abundant with a percentage ranging between 9 and $13 \%$. These results were in agreement with values found in the literature, for cattle $[15,16]$ and goats [3]. Regarding ewe milk, usually considered as a $\beta$-casein-rich milk, the percentage of $\alpha_{\mathrm{s} 1}$-casein was here slightly different than the previously reported results $[3,17]$, but in accordance with data summarized [18]. These discrepancies can be explained by several factors including sampling conditions, stage of lactation, animal breeds, etc.

\subsection{Translational efficiency of casein mRNA}

Whereas the four casein transcripts occur approximately at the same level of abundance in the mammary tissue (Fig. 2), the amounts of the corresponding proteins are by far different (Fig. 4). This strongly suggests that the four casein messengers are not translated with the same efficiency. In order to estimate their specific translational efficiency, we calculated for each casein the ratio: $\%$ of protein in milk to $\%$ of transcript in the mammary tissue. The results are given in Figure 5. $\beta$ - and $\alpha_{\mathrm{s} 1^{-}}$ casein mRNA show the highest translational efficiency, with ratio values 2.5 - to 4 -fold over the values recorded for $\alpha_{\mathrm{s} 2}$ - and $\kappa$-casein transcripts. The same results were observed in the three species.

mRNA translation is a complex multistep process taking place in the cytoplasm. It requires a large number of trans-acting factors as well as cis-sequence elements. Factors responsible for the differences in the translational efficiency of casein transcripts have to be found in structural ciselements mediating the initiation of translation, such as $\mathrm{m} 7 \mathrm{G}$ 5' cap, sequences flanking the AUG start codon, secondary structures within the mRNA leader sequence, etc. Conversely to prokaryotes, 


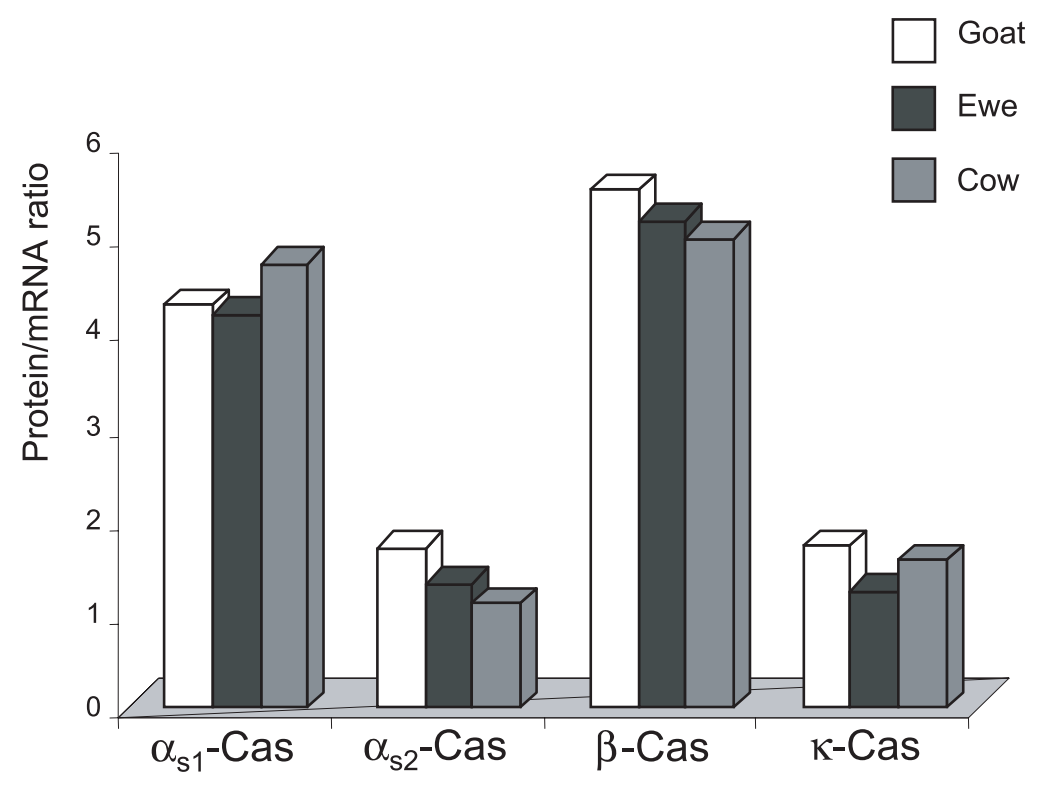

Figure 5. Translational efficiency for each casein in the three ruminant species studied. The specific translational efficiency is expressed as the protein (\% of whole casein in milk) to relevant mRNA (\% of the total amount of casein transcripts in the mammary tissue) ratio.

eukaryotic ribosomes routinely enter only at the 5' capped end of mRNA [19]. The subsequent scanning mechanism of initiation postulates that the $40 \mathrm{~S}$ ribosomal subunit, enters at the 5' end of the mRNA and then migrates linearly until it encounters the first AUG codon. The optimal context for initiation of translation in mammals is GCCRCCaugG [19]. In experimental tests, the strongest reduction in efficiency is seen when the purine $(R)$ in position -3 or the $G$ in position +4 is mutated. Thus, initiation sites are usually designated "strong" or "weak" based on these two positions. The GCCRCC motif (Kozak sequence) augments initiation only when it directly abuts the AUG codon.

Casein transcripts flanking sequences immediatly upstream of the initiation codon are well conserved between ruminant species and close to the consensus sequence but not strictly identical (Fig. 6). A favorable point for the four casein tran- scripts is that the Kozak sequence directly abuts the AUG initiation codon. The messenger displaying the most favorable context, with four positions conserved $A C A A C C$ over six in the GCCRCC consensus motif is the transcript coding for $\alpha_{s 1}$-casein. The other three messengers, encoding $\alpha_{\mathrm{s} 2}$ - and $\kappa$-caseins, and to a less extent that coding for $\beta$-casein with only 3 positions matching with the consensus sequence, can be considered as having a "weak" context. However, it is worth noting that the three nucleotides conserved as far as the $\beta$-casein transcript is concerned correspond to the last three residues directly upstream of the initiation codon. This could account for the high translational efficiency recorded with $\beta$-casein transcripts. Nevertheless, the occurrence of two consecutive AUG in the $\kappa$-casein messenger is probably not an optimal situation to ensure an efficient translation. Interestingly, it is the second AUG which seems to 


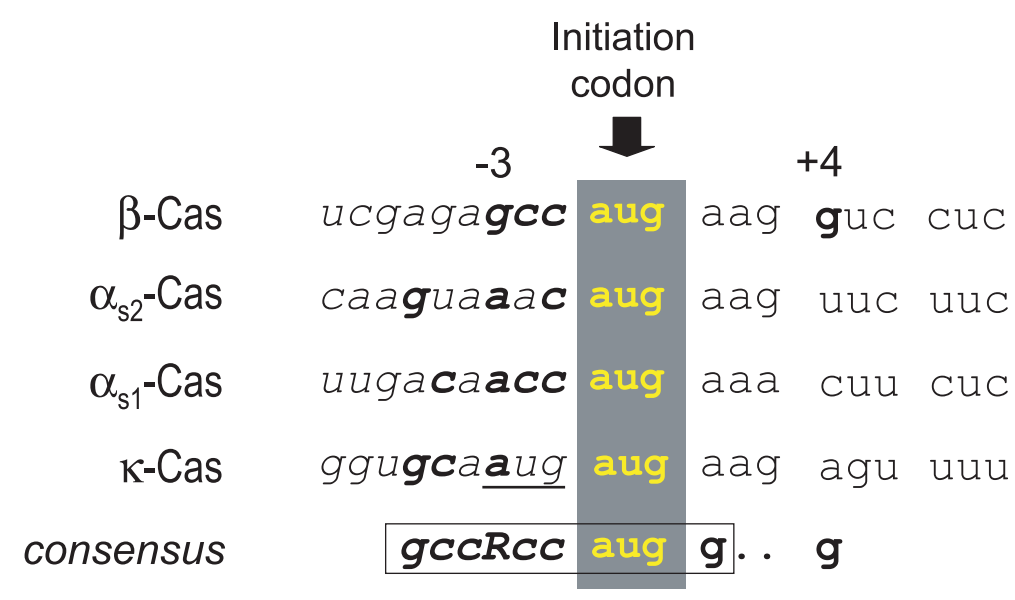

Figure 6. Comparison of start codon flanking sequences of the four casein transcripts, in the three species studied. Sequences given for each casein transcript are strictly conserved between cattle, sheep and goats. The optimal context for initiation of translation in mammals (Kozak consensus sequence [19]) is framed. The start codon in the four casein transcripts (AUG) is boxed (grey). Crucial -3 and +4 positions are indicated. Nucleotide residues in the 5'untranslated region are in italics. Nucleotide residues matching with the Kozak consensus sequence are in bold. $\mathrm{R}$ is a purinederived nucleotide (A or G). The first of the two consecutive AUG codons in the $\kappa$-casein transcript is underlined.

be used, probably due to a more favorable context. Taken together these data provide an acceptable explanation to account for the results observed, except for $\beta$-casein of which the transcript is efficiency translated. Careful analysis of flanking sequences in the $\beta$-casein transcript, revealed that the start codon is flanked by G-3 and G+4 which can enhance up to 10 -fold the efficiently of an AUG codon in the weakest context [19]. However, the strong positive effect of $\mathrm{G}+4$ has to be relativized since it is followed by a $U$ of which the occurrence in position +5 has been reported to have a negative effect on translation initiation [20].

\section{CONCLUSIONS}

In summary, here we show, for the first time, that the four casein messengers are not translated with the same efficiency. Indeed, even though the four casein tran- scripts occur approximately at the same level of abundance in the lactating mammary tissue, which does not mean that the four genes are equally transcribed, the amounts of the corresponding proteins in milk are different. Thus, $\alpha_{s 1^{-}}$and $\beta$-casein transcripts are translated ca. 3- to 4-fold more efficiently than $\alpha_{\mathrm{s} 2}-$ and $\kappa$-casein transcripts. This seems to be the rule in cattle as well as in goats and sheep. Differences in the mRNA leader region (cisacting elements such as the Kozak sequence) might explain, at least in part, the differential translational efficiency between the two classes of casein mRNA.

This preliminary experiment which provides a rational explanation to the ruminant milk casein distribution (approximate weight proportions $4: 1: 4: 1$ for $\alpha_{s 1}: \alpha_{s 2}: \beta: \kappa$, respectively), has to be extended to a larger number of individuals to confirm and strengthen our findings and conclusions. 
However, it is unwise to look only at sequence context surrounding the initiation codon and to ignore either possible secondary structures in the mRNA 5' leader sequence or forget abundant evidence implicating 3' UTR elements in translational regulation [21]. Indeed, Tanguay and Gallie [22] have shown that the length of the 3'UTR plays an important role in determining both the translational efficiency and the stability of an mRNA. Eventhough our experimental approach was not designed to see which way of post-transcritional gene regulation is prevaling, the genetic polymorphism occurring at the goat CSN1S1 locus provides us the opportunity to discriminate between stability and translation efficiency. Quantitative comparisons of $\alpha_{s 1}$-Cas mRNA from different genotypes (A/A vs. A/E) allows to estimate the contribution of each allele. The normalized amount of $\alpha_{\mathrm{s} 1}$-Cas transcripts was 1.08 with homozygous $\mathrm{A} / \mathrm{A}$ whereas it was 0.62 with heterozygous A/E. Then the contribution for each allele would be 0.54 and 0.08 for $\mathrm{A}$ and $\mathrm{E}$, respectively, with a $\mathrm{A} / \mathrm{E}$ ratio close to 7. This is in agreement with previous results [10] showing that the amount of transcripts arising from the E allele is significantly lower than that encoding the $\alpha_{\mathrm{s} 1}$ casein A variant. It had been hypothesized that the presence of a truncated LINE insertion (containing AU-rich motifs) within the last untranslated exon of this allele could be responsible for a reduced stability of the E allele mRNA. Given the amount of $\alpha_{\mathrm{s} 1}$-casein: 3.6 vs. 1.6 g.L $\mathrm{L}^{-1}$, per allele [23], for $A$ and $E$ variants, respectively (A/E ratio 2.25$)$, our results suggest that the longer transcript (E) would be less stable but translated more efficiently. A similar observation has been pointed out recently for two rat 5' deiodinase (D1) mRNAs, resulting from differential polyA signal usage [24]. A detailed analysis of the four casein transcripts 3'UTR in the three ruminant species provides further evidences in this direction. Actually, the most two efficiently translated mRNAs $\left(\alpha_{\mathrm{s} 1}\right.$ and $\beta$-caseins) show the longest 3'UTR (431/434 and 358/377 nt, respectively) while their counterparts are only 299 and 214/227-nt long for the transcripts encoding $\alpha_{\mathrm{s} 2^{-}}$and $\kappa$-casein, respectively. In addition, short but rather well-conserved sequence motifs have been found within the 3'UTR of the first two casein transcripts but alternatively lacking in $\alpha_{\mathrm{s} 2-}$ and $\kappa$-casein mRNAs. Finally, translational efficiency of the four casein transcripts appears to be potentially modulated by multiple regulatory elements which have to be found within 5' and 3' untranslated regions.

To go further in the understanding of underlying mechanisms such hypotheses have now to be sustained. We plan to construct recombinant plasmids in which 5 , and 3'UTR sequences of the four casein transcripts will be cross-exchanged (by replacing the 3' UTR of $\alpha_{\mathrm{s} 1}$-casein mRNA with that of the $\kappa$-casein mRNA and vice versa) and subsequently used for in vitro translation experiments.

\section{ACKNOWLEDGEMENTS}

We are grateful to J. Chirac for pertinent and helpful advices and for his financial support. Many thanks to Didier Boichard, head of the Department of Animal Genetics who funds the CB Post doc fellowship. Thanks to the INRA CRJ Functional Genomics Facility (Pict) where quantitative real time PCR experiments were performed.

\section{REFERENCES}

[1] Rijnkels M. Multispecies comparison of the casein gene loci and evolution of casein gene family. J Mammary Gland Biol Neoplasia 2002, 7: 327-345.

[2] Farrell HM Jr, Jimenez-Flores R, Bleck GT, Brown EM, Butler JE, Creamer LK, Hicks CL, Hollar CM, Ng-Kwai-Hang KF, 
Swaisgood HE. Nomenclature of the proteins of cows' milk-sixth revision. J Dairy Sci 2004, 87: 1641-1674.

[3] Miranda G, Mahé MF, Leroux C, Martin P. Proteomic tools to characterize the protein fraction of Equidae milk. Proteomics 2004, 4: 2496-2509.

[4] Kunz C, Lönnerdal B. Human-milk proteins: analysis of casein and casein subunits by anion-exchange chromatography, gel electrophoresis, and specific staining methods. Am J Clin Nutr 1990, 51: 37-46.

[5] Chtourou A, Brignon G, Ribadeau Dumas B. Quantification of beta-casein in human milk. J Dairy Res 1985, 52: 239-247.

[6] Stevenson E, Leaver J. Chromatographic separation of the proteins of mouse milk. Int Dairy J 1994, 4: 205-220.

[7] Dawson SP, Wilde CJ, Tighe PJ, Mayer RJ. Characterization of two novel casein transcripts in rabbit mammary gland. Biochem J 1993, 296: 777-784.

[8] Martin P, Szymanowska M, Zwierzchowski L, Leroux C. The impact of genetic polymorphisms on the protein composition of ruminant milks. Reprod Nutr Dev 2002, 42: 433-459.

[9] Grosclaude F, Martin P. Casein polymorphism in the goat. IDF-FIL Seminar Milk Protein Polymorphism II Internation Dairy Federation, Palmerston North, New Zealand, Proceedings 1997, p 241-253.

[10] Jansà-Pérez M, Leroux C, Sànchez-Bonastre A, Martin P. Occurrence of a LINE sequence in the 3' UTR of the goat alphaS1caseinE-encoding allele associated with reduced protein synthesis level. Gene 1994, 147: 179-187.

[11] Leroux C, Mazure N, Martin P. Mutations away from splice site recognition sequences might cis-modulate alternative splicing of goat alphaS1-casein transcripts. Structural organization of the relevant gene. J Biol Chem 1992, 267: 6147-6157.

[12] Leroux C, Amigues Y, Jansà-Pérez M, Martin P. Polymerase chain reaction (PCR)based RFLP genotyping of alphaS1-casein. Livest Prod Sci 1993, 35:193-194.

[13] Visser S, Slangen CJ, Rollema HS. Phenotyping of bovine milk proteins by reversed-phase high-performance liquid chromatography. J Chromatogr 1991, 548: $361-370$.

[14] Schroeder A, Mueller O, Stocker S, Salowsky R, Leiber M, Gassmann M,
Lightfoot S, Menzel W, Granzow M, Ragg T. The RIN: an RNA integrity number for assigning integrity values to RNA measurements. BMC Mol Biol 2006, 7: 3.

[15] Walstra P, Jenness R, Protein composition of milk. in: Walstra P, Jenness R (Eds), Dairy chemistry and physics, Wiley, New York, 1984.

[16] Bobe G, Beitz DC, Freeman AE, Lindberg GL. Separation and Quantification of Bovine Milk Proteins by Reversed-Phase High-Performance Liquid Chromatography. J Agric Food Chem 1998, 46: 458-463.

[17] Martin P, Grosclaude F. Improvement of milk protein quality by gene technology. Livest Prod Sci 1993, 35: 95-115.

[18] Bramanti E, Sortino C, Onor M, Beni F, Raspi G. Separation and determination of denatured alphaS1-, alphaS2-, beta- and kappacaseins by hydrophobic interaction chromatography in cows', ewes' and goats' milk mixtures and cheeses. J Chromatogr 2003, 994: 59-74.

[19] Kozak M. Regulation of translation via mRNA structure in prokaryotes and eukaryotes. Gene 2005, 361: 13-37.

[20] Kozak M. Recognition of AUG and alternative initiator codons is augmented by $\mathrm{G}$ in position +4 but is not generally affected by the nucleotides in positions +5 and +6 . EMBO J 1997, 16: 2482-2492.

[21] Wickens M, Goodwin EB, Kimble J, Strinckland S, Hentze M. Translational control of developmental decision. In: Sonenberg N, Hershey JWB, Mathews MB (Eds), Cold Spring Harbor Press, New York 2000, p 295-370.

[22] Tanguay RL, Gallie, DR. Translational efficiency is regulated by the length of the 3' untranslated region. Mol Cell Biol 1996, 16: 146-156.

[23] Grosclaude F, Martin P. Casein polymorphisms in the goat. IDF seminar Milk Protein Polymorphism II, International Dairy Federation, Palmerston North, New Zealand, 1997, p 241-253.

[24] Arroyo-Helguera O, Mejia-Viggiano C, Varela-Echavarria A, Cajero-Juarez M, Aceves C. Regulatory role of the 3' untranslated region (3'UTR) of rat deiodinase (D1). Effects on messenger translation and stability. Endocrine 2005, 27: 219-225.

[25] Rijnkels M, Elnitski L, Miller W, Rosen J. Multispecies comparative analysis of a mammalian-specific genomic domain encoding secretory proteins. Genomics 2003, 82: 417-432. 